\title{
Rose surprise: when your period comes early
}

Hope Bretscher

You have just got to the lab on a Monday morning, and are planning on working there until your afternoon lecture. As soon as you sit at the data analysis computer, you feel a tightening in your abdomen, and realise that soon, you'll receive a rosy surprise down yonder. Surprise! Your period came unexpectedly, and you failed to prepare. Here's a nice recipe on how to use up that unwanted ingredient spilling from your cupboard.

\section{Ingredients}

- A labful of men.

- No women (other than you).

- One period.

- One backpack (and its contents).

\section{Method}

1. Search your backpack frantically, making sure to sufficiently mix its entire contents. You do not find a tampon.

2. Go to the bathroom and confirm that you have the third ingredient (as this is essential and cannot be substituted).

3. Search your backpack again, thoroughly stirring its contents. You can be slow and methodical or mix rapidly, by pulling everything out and stuffing it back in. Use whatever suits your personal taste.
4. Check your phone and remember that you work in the laboratory sub-basement where there is no cell reception or wifi to prevent interference with the experiments.

5. Wait for a few minutes, until your postdoc mentor leaves the room, and then mix your backpack for the third time. Vigorous searching creates the best taste.

6. Go to Facebook and GMail on the desktop computer and send a plea to your girl friends to see if they are near your lab building.

7. Sigh when they are not.

8. Whoops! Your postdoc has returned, so close social communication and return the screen to MATLAB work mode.

9. Type angrily in frustration.

10. Your frustration has simmered enough. Take a breath, and remind yourself that it's fine to leave the lab to go to the shop for some tampons and painkillers. Don't let the pain stew and simmer any longer. 


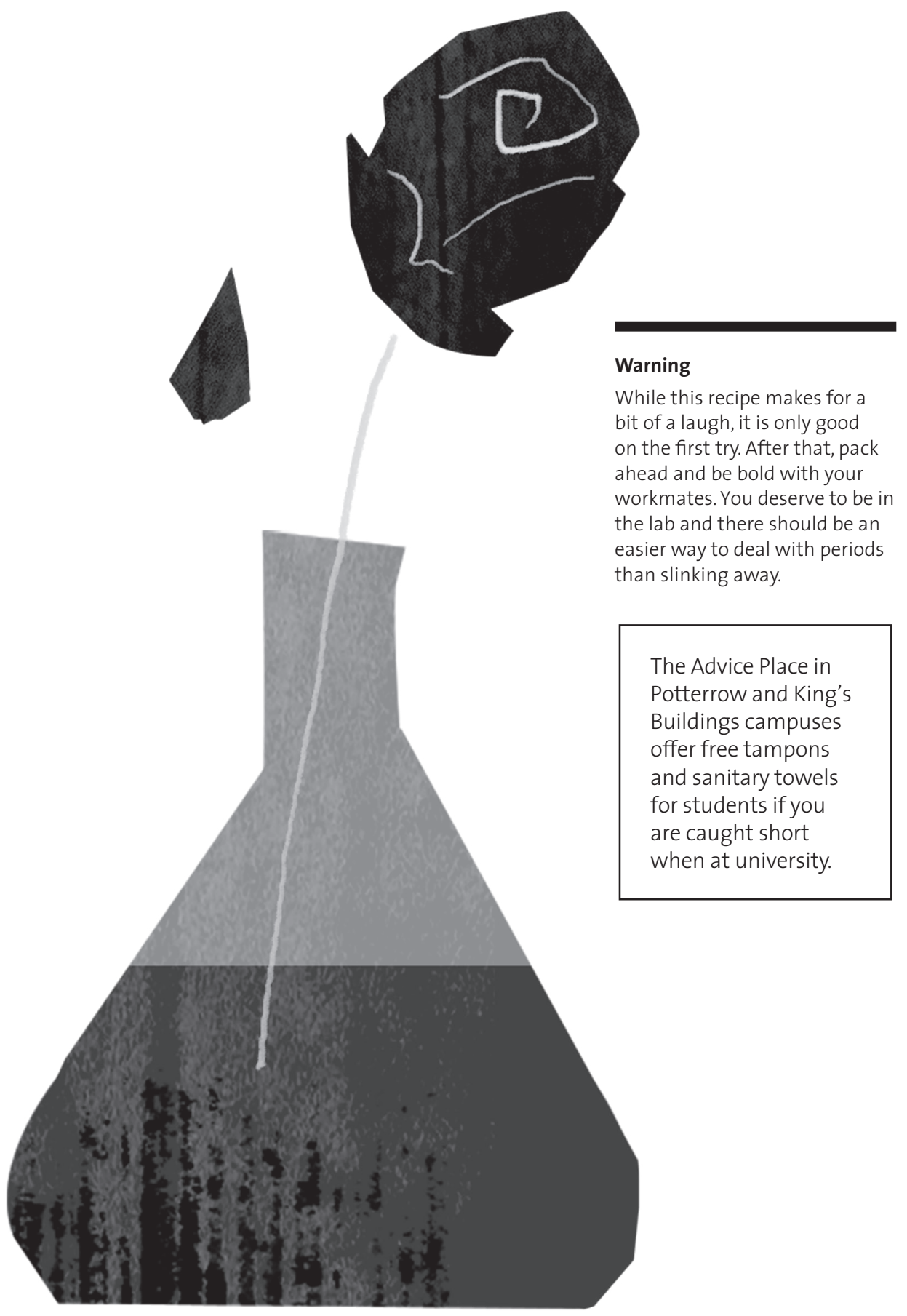

